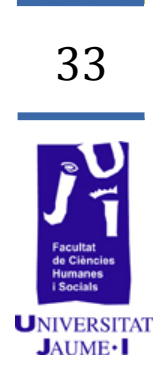

\title{
¿Puede la persona-masa aspirar a la lucha vital? Reflexiones orteguianas en la máxima actualidad
}


La pregunta del título nos permitirá adentrarnos en la filosofía orteguiana y en conceptos claves de máxima actualidad, que sin saberlo nos afectan día a día. Vida, trabajo, minoría o masa tienen una perspectiva vigente y muy especial para Ortega y Gasset. Podremos replantearnos conceptos que aparentemente tenemos muy definidos. Conoceremos lo que Ortega llamó el síndrome por excelencia del europeo junto a los tipos de personas y problemas derivados que conlleva. ¿En qué momento "trabajar para vivir» pasó a ser «vivir para trabajar»? Ortega propone una respuesta muy interesante. Analizó un sistema lleno de trampas y deficiencias estructurales por mucho tiempo desapercibidas y con funestas consecuencias.

Reflexionaremos y uniremos los conceptos hasta acercarnos mejor a nuestra actualidad y cotidianeidad. Gracias a su obra, buscaremos dar salida a los problemas estructurales de la occidentalidad y la Ilustración en el ámbito personal, social, continental e incluso mundial. Lo relacionaremos con la crisis del pensamiento del siglo $\mathrm{xX}$, tanto en la antesala como sus consecuencias y nos articularemos con la obra y biografía de un autor nuestro y muy cercano, que nos permitirá actuar como bisagra en este viaje filosófico.

Esta lectura también servirá como una introducción e invitación a leer dos obras imprescindibles como son El tema de nuestro tiempo o La rebelión de las masas. Veremos la propuesta de un sabio profético y su modelo para triunfar y aprovechar la vida (la lucha vital), al fin y al cabo, es nuestra identidad y circunstancia; que se vuelve un concepto muy valioso y presente en la sociedad de las masas. Al mismo tiempo, veremos cómo se puede conectar con otros autores clásicos o modernos demostrando la plasticidad de su pensamiento.

Palabras clave: Ortega y Gasset, minoría selecta, persona-masa, lucha vital, trabajo, cultura, razón y raciovitalismo.

\section{Introducción}

Como dirá Gasset: ¿la máxima actualidad y la tradición europea occidental son compatibles? ¿Nuestra vida y sociedad gozan verdaderamente de valores y sentido? ¿O camuflado entre muchos lujos y falsas necesidades; viajamos rumbo a un nihilismo hueco, sin sentido e inevitable? ¿Existe esperanza para una sociedad plagada de personasmasa? ¿Se puede evitar verdaderamente serlo en nuestros días? ¿Hemos perdido o simplemente renunciado a la lucha vital? A lo largo de estas páginas, buscaremos responder a estas y otras preguntas. Este humilde artículo es la ampliación y maduración de un trabajo de la asignatura Filosofía Moderna y Contemporánea que realicé en tercero de carrera, 
donde trabajábamos a un autor libre. Su evolución me permitió llevarlo positivamente a las jornadas presentes en esta revista.

Dos de sus obras principales: El tema de nuestro tiempo (1923) y La rebelión de las masas (1929) serán las principales acompañantes en nuestro viaje filosófico. La elección de ambos libros responde a su elevado grado de conexión y el segundo, en cierto modo, es la respuesta al debate abierto del primero. Al mismo tiempo, permiten presentar al lector los conceptos básicos orteguianos: la primera obra explica el raciovitalismo -revisando el espíritu racional e ilustrado-como propuesta integradora y regeneradora de la filosofía con el resto de facetas de la vida. Al mismo tiempo, la segunda recoge una sociología filosófica muy vigente; en la que distingue entre persona-masa y la minoría excelente.

En su conjunto se muestra una perspectiva distinta sobre la vida, cultura o Europa tal y como explicaremos a lo largo del trabajo. No responde a la mera crítica ácida o pesimista que no propone alternativas. Más bien todo lo contrario, ya que se puede vislumbrar una fuerte esperanza en el futuro de la humanidad en sus palabras. Sin embargo, simultáneamente se muestra muy receloso y se mantiene alerta con una civilización que si nos descuidamos acabará desapareciendo. Ortega era consciente de la delicada situación del mundo del pensamiento, la vida y el mundo en su conjunto tras la crisis del pensamiento de la modernidad. Pues había dejado un mundo ambiguo y en crisis, necesitado de respuestas urgentes y acertadas para reorientarse en su práctica totalidad (Gambra, 1987, y Russel, 2011), como iremos viendo más adelante. Por cuestiones cronológicas, no pudo ver todos los cambios, pero en cierto modo sí que supo hacer una acertada lectura del mundo del momento y de sus posibles variaciones.

Como aportación personal, su lectura con tintes proféticas que suponía una fuerte carga contra la tradición occidental ha transmitido en cierto modo la labor de los maestros de la sospecha (Marx, Freud y Nietzsche), en el sentido de criticar el mensaje oficial vendido como el definitivo y reinterpretarlo. En el conjunto de su obra, Ortega hablará del trabajo, de los instintos... como los autores anteriores comentados.

\section{Objetivos}

«¿Puede aspirar la persona-masa a la lucha vital?». Con esta pregunta -como título del trabajo- buscamos perseguir múltiples fines: el primero es acercar e incentivar al lector a leer la obra de un filósofo cercano a nuestra cultura, de prosa fácil y cercano como es Ortega y Gasset. En segundo lugar, recuperar una visión de filosofía más viva y cercana como intérprete de su sociedad y su rumbo (pasado, presente y futuro). En tercer lugar, la prioridad es comentar, cohesionar y relacionar ambas obras con otros autores clásicos mientras se suman aportaciones personales con cierto interés y habilidad. Finalmente, plantear al lector una serie de cuestiones -tanto directas como indirectas- que inviten a aprender algo nuevo y reflexionar. 
En cuestión de método, reside en un modelo más hermenéutico crítico, tras una lectura y maduración de los conceptos, nos adentramos en una interpretación y comprensión personal como propuesta de investigación.

La base de este proceso es la lectura de dos libros clave en la obra de Ortega y Gasset, como hemos explicado en la introducción. Para contextualizar su pensamiento se han empleado varios libros de la historia del pensamiento y su vinculación con los hechos históricos, aunque nos centraremos más en occidente propiamente. Nos referimos a Russell (2011) y Gambra (1987). Al mismo tiempo lo vinculamos con autores como Aristóteles (Aristóteles, 2015) o Kant (Kant, 2001) entre cuyos conceptos se pueden percibir muchas similitudes.

\section{Resultados}

Repasaremos aquí la estructura del trabajo, con el fin de delimitarlo un poco y permitir al lector alcanzar una visión más conjunta e interconectada de la investigación. En primer lugar, situaremos el contexto filosófico con datos breves sobre José Ortega y Gasset. Consideramos clave la necesidad de presentar al autor relacionándolo con su biografía vital. Por dos motivos: por un lado, por norma general, tras una contextualización biográfica se suelen entender mejor los conceptos y las reflexiones. Por otro lado, como motivo más concreto, Ortega le da gran importancia a la vida y como es vívida para marcar la identidad, dando a entender que somos el cúmulo de circunstancias y esfuerzo. Todos arrastramos las decisiones constantes e interminables "obligados» por nuestra libertad, junto al mayor o menor respeto y aceptación de nuestra genuinidad (Ortega y Gasset, 1981 y 1990). Por coherencia con el trabajo, debemos incluir necesariamente un bloque de este tipo.

En segundo lugar, analizaremos conceptos, corpus y propuesta de Gasset intentando aunarlos en un único cuerpo reflexivo.

En tercer lugar, un breve apartado donde se vinculará el autor a la máxima actualidad, de forma que se analizamos así lo profético. Finalmente, las conclusiones alcanzadas, de forma breve, a modo de síntesis final.

\subsection{Ortega, biografía y su contexto filosófico}

La humanidad se encuentra en uno de sus peores y más influyentes períodos: la primera mitad del siglo xx. Son problemas que afectan a todo el mundo: la explosión del imperialismo, la subida de los fascismos o el impacto de la Primera y de la Segunda Guerra Mundial, etc., entre otros muchos hechos decisivos. Todos supusieron una crisis severa reflejada en reflexión, revisión y crítica sobre la cultura occidental. Así los valores y fe 
ciega en la modernidad y las ciencias naturales quedan en duda. Además, la filosofía queda especialmente desprestigiada por la pérdida de la fuerza crítica e identidad, y tiende más a la pura imitación de las ciencias naturales o a la radicalización ideológica Russell (2011) y Gamba (1987).

En todo este proceso se plantearon diversas preguntas en un mundo perdido y en caos, y se abarcaron múltiples aspectos de la vida y la cultura: ¿Podemos mantener el mismo tipo de sistema y modelo de ciencia? ¿Debemos volver a nuestros orígenes, probar algo verdaderamente nuevo o formular un hibridismo de todas las posturas? ¿Existe un futuro para el campo social de las humanidades? ¿Qué ocurrirá con cada individuo si nada tiene ya sentido? ¿Y con Europa? ¿Y el mundo?

A raíz de todos estos cambios, un nuevo período filosófico crítico y urgente se encargará de revisar la filosofía occidental. Como respuestas distintas a un mismo problema aparecen a la vez muchos autores y corrientes: la posmodernidad, la Escuela de Frankfurt, recuperación de la hermenéutica y nuevos modelos de hacer ciencia, etc. Poco a poco se fue abandonando en parte la supremacía de la conciencia y la razón del período moderno y se alcanzó el paradigma del lenguaje caracterizado por la comunicación y el diálogo (Russel, 2011 y Gamba, 1987). Por cuestiones de extensión, no ampliaremos más el contexto histórico y filosófico general.

¿Qué relación exacta mantiene Ortega con este plano filosófico? Por biografía (1883-1955) se volverá testigo de la modernidad en sus últimos años: con el peso occidental en su máximo exponente -el período imperialista- junto a su decadencia -las dos guerras mundiales. Al mismo tiempo, en su vejez verá cómo nace el inicio del cambio: una generación que busca la necesaria crítica y regeneración y se muestra más activa y dialogante, y convivía al mismo tiempo con un mundo que se iba dividiendo con dos modelos sucesores en la Guerra Fría. Ahí es donde entra nuestro autor como fina bisagra entre esta transición difusa y cambiante entre el período que va tras la crisis de la modernidad y un mundo completamente abierto; con la responsabilidad de aprovechar y aprender lo previo, para alcanzar entre todos un mundo mejor o de repetir formulas y sistemas destinadas al fracaso y el conflicto.

En cuanto a lo más biográfico y personal, José Ortega y Gasset (18831955) es un filósofo y ensayista español con una obra prolífica decisiva, situada en la primera mitad del siglo xx. Como hijo de la aristocracia burguesa madrileña, estudió en la Universidad Central de Madrid donde se doctoró en Filosofía y Letras. Complementó su formación en Alemania de donde recibió importantes influencias, especialmente de Kant (Ortega y Gasset, 1981).

En mi opinión, su filosofía se caracteriza por combinar lo profético, lo periodístico y lo cotidiano. Ortega anticipó -o al menos intuyó- el tipo de sociedad e individuos de las décadas posteriores. Un logro especialmente destacable en un mundo tan convulso y protagonizado por el imparable cambio. Al mismo tiempo, expone duramente los problemas de la sociedad europea y española tras perder la fuerza vital y el lugar que les 
pertenece. Todas estas críticas le llevan a proponer un modelo personal de filosofía: el raciovitalismo.

Como intelectual, siempre quedará vinculado al mundo periodístico y político, muy constantes en su vida. A continuación, exponemos datos significativos para acercarnos a su ideología y postura política: la oposición tajante a Primo de Rivera, un fuerte compromiso público y universitario a la República. Se exilió en muchos países de Europa y ambas Américas antes y durante la Guerra Civil, lo que le permitió extender su obra a lo largo del mundo y se dio a conocer con inmediato éxito. Volvió en 1955, el mismo año de su muerte, en Madrid (Ortega y Gasset, 1990).

\subsection{Reflexión sobre el corpus filosófico orteguiano}

Este bloque interno lo dividiremos en tres apartados: el primero con el nombre de "Problemas derivados de la confusión entre vida y trabajo», donde nos centraremos en el raciovitalismo. En el segundo, «Personamasa, minoría selecta y la lucha vital», hablaremos de la antropología orteguiana. Concluiremos con el apartado «¿La lucha vital posible tras la crisis mundial de la primera mitad del siglo xx?», donde aunaremos los dos libros y los relacionaremos con la realidad mundial de las últimas décadas hasta la actualidad.

\subsubsection{Problemas derivados por la confusión entre vida y trabajo}

Antes de empezar a filosofar, cabe advertir al lector de la siguiente observación: El tema de nuestro tiempo (1923) se escribió seis años antes. Lo destacamos por dos motivos: por un lado, buscamos asentarlo como base principal de la estructura conceptual. Por otro, queremos contrastarlo y complementarlo con La rebelión de las masas. Nuestro reto es averiguar las variaciones y evoluciones del pensamiento orteguiano en ese intervalo de tiempo. Una vez matizado nuestro modo de proceder iniciamos con las principales reflexiones.

Como curiosidad previa, ambas obras cuentan con un prólogo tanto para ingleses como alemanes. En nuestra opinión no es una casualidad, el hecho de que en ambos casos se repitiera este criterio expone claramente dos observaciones: por una parte, el éxito en vida de Ortega era notable; por otro debía explicar muchos matices que, como él expresa contantemente, solo entenderá el público español o latinoamericano. Pese a que su obra tiene un marcado carácter nacional, su éxito y la aplicación de ideas se extiende a todo el continente y al mundo como la pólvora de la época.

En El tema de nuestro tiempo, Ortega altera las ideas tradicionales de existencia de cuerpo y alma; pasan a transformarse en cultura y vida dentro de su universo filosófico. O lo que es lo mismo: razón y biología. Antes de decir nada, a priori es evidente saber que está mejor valorado. Desde la modernidad marcada por la llustración, lo intelectual siempre ha gozado de una mejor valoración respecto a lo corporal, aunque tiene sus 
matices, pues la apariencia física siempre ha estado presente, por ejemplo.

Así, poco a poco e inconscientemente, naturalizamos lo artificial (en este caso nuestros pensamientos e ideas). En esa transformación, lo que antes era propiamente natural (lo biológico) se queda sin sitio (Ortega y Gasset, 1981).

Mientras la jerarquía tradicional se altera, la vida y el cuerpo se vuelven innecesarios, menores o inapropiados. Así, esta conducta reniega del principio vital. Para Ortega, ¿no es lo más ilógico, ridículo y antinatural a lo que podría aspirar una persona? Se percata de que este paradójico proceso es único y genuino de lo europeo, ya que el resto de continentes han sabido compaginar mejor ambos universos -0 al menos no renunciar al otro.

Esta peculiaridad europea se ha radicalizado y ha llevado a la quiebra de la propia modernidad, como consecuencia principal, el concepto de ciencia, y especialmente la filosofía -tal y como acentuábamos en el contexto. Para Ortega, esta incapacidad de combinar ambos universos es sin duda la verdadera causa de todo, de la crisis interna y falta de identidad de Europa (Ortega y Gasset, 1981).

Curiosamente, como pequeño paréntesis personal, nos da la sensación de que aún hoy cuesta compaginar ambas facetas de la vida: desterrando la vida por un mundo cultural con una gran presencia del trabajo -uno de sus principales factores- pues es una de las vías de más aprendizaje y tiempo dedicado.

Un ejemplo evidente es que, en la sociedad actual, el concepto de vacaciones es renegado -cuando están comprobados sus beneficios para la salud y la vida-, y ya suele costar que la gente se las coja voluntariamente. Aun así, no se desconecta completamente; pues se sigue vinculado a través del teléfono móvil o el ordenador. Incluso peor, no se disfruta ni se aprovecha del tiempo libre pensando en las tareas pendientes o viendo peligrar el puesto de trabajo; y todo favorecido por el neocapitalismo, por su excesiva competitividad o incluso el despido. El segundo, en ocasiones, sale rentable $o$ es una herramienta de intimidación infalible. Se deshumaniza completamente el factor humano y el antiguo sentimiento de protección y relajación de tener un trabajo; es decir, lo que permitía construir tu proyecto de vida. Sin embargo, ahora todo es frívolo y maquiavélico, la ausencia estructural de trabajo ha vuelto al mercado laboral chantajista, masificado y frívolo: encontrar un sustituto dispuesto a trabajar por menos salario es fácil y seguro. Desde nuestra perspectiva, todo esto sucede por la alteración de jerarquías naturales -comentadas anteriormente- $y$ priorizar trabajo sobre vida hasta las últimas consecuencias.

¿Existe mayor suicidio vital que sacrificar nuestro ocio constantemente? Al fin y al cabo es necesario para vivir, evadirse, descansar y construir nuestra personalidad. Observando las ideas expuestas por Ortega, si nuestro autor pudiera ver el clima laboral actual diría que no hemos acabado de compensar, ni mucho menos, la balanza 
expuesta en el raciovitalismo. Más bien hemos ampliado aún más ese mundo obsesionado con el trabajo, con la infelicidad que trae cualquier radicalización y huida del término medio. Todos estos excesos nos alejan de perseguir el verdadero fin individual de cada uno, que uno mismo debe encontrar y que no coincide con el mensaje del sistema de «vivir para trabajar» (Aristóteles, 2015). Hace mucho que, como sociedad, superamos "el trabajar para vivir» y las consecuencias son visibles cada día.

Para Ortega, conocimiento real -es decir, de la realidad, aparentemente evidente, pero a veces parece que aún es necesario matizar- solo se puede aspirar mediante la propia vida, como único camino sensato y eficiente. Cuidado lector, ya sé que parece que Ortega renuncia a la razón, pero nada más lejos. Solo destaca que la cultura debe trabajar para la vida y no lo que sucede actualmente: una vida sacrificada por la razón y la cultura. Si no, entramos en una radicalización donde vida, sexualidad y cuerpo quedan secuestradas. A día de hoy parece que hemos malinterpretado el concepto y umbral de ciencia, seguramente por la influencia de movimientos o corrientes como el positivista (Ortega y Gasset, 1981: 24):

En cada instante necesitamos vitalmente y con cierta urgencia estar en claro sobre determinadas cuestiones. La ciencia tiene la obligación de no ocuparse solo de problemas gremiales, "técnicos», de taller. Está ahí, en definitiva, para resolver en todo instante el repertorio de respuestas a las preguntas vivas.

Ortega observa que el gran peligro de la razón, las ideas y las abstracciones se acaban convirtiendo en unos peligrosos fetiches. Se les otorga de un poder infalible, controlable e ilimitado, capaz de cuadricular la verdad. Así, la razón se integra inocentemente y abiertamente a nuestro servicio. Por tanto, como mínimo debemos recelar de cualquier principio cuadriculado, pues la vida no es ni mucho menos perfecta o lógica; es mucho más compleja que cualquier esquema (Ortega y Gasset, 1981).

Desde nuestro punto de vista y apoyándonos en Russel (2011), podemos volver a caer en la paradoja de la Diosa Razón donde una razón se radicaliza, y atribuye los atributos de fe y superstición (infalible, único, compartido, empoderante). Por lo tanto, las incompletas maneras de guiar las vidas y sociedad que venía a superar y sustituir acaban repitiendo los mismos errores con distinta fórmula. Destaco este proceso, porque fue uno de los déficits más importantes del sistema planteado por la modernidad y ya se dio en los propios revolucionarios franceses con funestas consecuencias.

Como pequeña apreciación, transmitir de lo teórico a lo práctico resulta la verdadera capacidad de comprensión y un momento complejo de gestionar: pasar de la mente a la práctica real y compartida. Entendemos que los pensamientos de Ortega siguen esta vía. Todo este proceso lo explica perfectamente Ortega (1981: 109 y 117): 
Se creía que se creía en la cultura; pero, en rigor, se trataba de una gigantesca ficción colectiva de que el individuo no se daba cuenta porque era fraguada en las bases mismas de su conciencia.

$[\ldots]$

La razón es solo una forma y función de la vida. La cultura es un instrumento biológico y nada más. [...] Urge reducirla a su puesto y oficio.

Desde nuestro punto de vista, ¿cuál es el verdadero error que recrimina Ortega a Europa occidental? Lleva enfrentado ambos modelos toda la vida desde sus orígenes (por ejemplo, el choque entre el mito y el logos): Ortega propone simplemente -que no es tan fácil y menos para el "europeo medio»- integrarlos. Esta situación es parte natural, pues se manifiesta ya en época clásica y sigue, por así decirlo, varias modas. Pondremos un ejemplo: Grecia clásica - razón y helenismo - vida. Ya en los orígenes de la cultura grecolatina se muestra una severa dualidad.

Desde un principio, Ortega mantiene que la vida permite gozar de una mente abierta que permita sobrevivir y adaptarse. Así pues, perspectiva vital equivale a ganancia y aportación como vemos en las siguientes citas: "La perspectiva es uno de los componentes de la realidad. Lejos de ser su deformación, es su organización» (Ortega y Gasset, 1981: 147). Vemos cómo se anticipa la importancia de salir del modelo puramente occidental, buscar otros modelos y fórmulas e intentar ir más allá. Para construir esa opinión, se nutre en gran parte de la experiencia vital, gracias a la que adquirimos nuestra unicidad y capacidad de aportar una opinión irrepetible y distinta: "Cada vida es un punto de vista sobre el universo. En rigor, lo que ella no puede ver no lo puede ver otra. Cada individuo -persona, pueblo, época- es un órgano insustituible para la conquista de la verdad». (Ortega y Gasset, 1981: 148).

Finalmente, Ortega se mostró opuesto a los dogmatismos y al modelo monológico que no permitían el diálogo, seguramente influenciado por el horror de los fascismo y las dictaduras de su país. La necesidad de múltiples perspectivas, combinada con huir de la pura y frívola homogenización de opinión (cuyo peligro principal era el estancamiento masivo como sociedad y el falseamiento de la vida e identidad como individual), se volvió un concepto clave y continuo en su obra. Como viene recogida en la siguiente cita, "La sola perspectiva falsa es esa que pretender ser la única» (Ortega y Gasset, 1981: 149).

Afortunadamente, con el cambio de paradigma de la conciencia en crisis después de todos los hechos históricos comentados, cobró fuerza la comunicación y el diálogo dentro del paradigma del lenguaje. Así, se dio lugar a un mundo de multiperspectivismo orteguiano.

Sin embargo, esa oportunidad no quita que la sociedad le cueste recuperar la lucha vital en la actualidad ante una peligrosa ola estandarizante de la sociedad de masas. Como se intuye por etimología, muy vinculada con la persona-masa orteguiana y sus aglomeraciones (Ortega y Gasset, 1990). 
No en vano, una de sus principales aportaciones es analizar el espíritu, la ideología y salud de Europa y el europeo, como una especie de tratamiento médico al individuo y su sociedad. Siguiendo la metáfora, la única cura para sus problemas es el raciovitalismo. La ignorancia completa de su enfermedad aún lo agrava más. Tal y como ya acontecieron los Maestros de la Sospecha, Europa no era consciente de su propia e inevitable caída ante los errores estructurales de planteamiento.

Para Ortega, Europa ha enfermado y ha parado el rumbo de toda la civilización. Comprender que la razón no puede ser absoluta ni integrar todo después de una larga tradición culturalista es el gran reto de un europeo que ha olvidado vivir entre tanta técnica e idea teórica y suprema (Ortega y Gasset, 1981).

Como pequeño análisis personal, sin duda un factor que justifique la situación explicada por Ortega es la herencia de las principales creencias religiosas, pues siempre han abogado que la importante es la otra vida: de manera más consciente o no hemos bebido de «aquí en el mundo terrenal estamos para sufrir y trabajar» y la cultura de la culpa. De ahí seguramente se deba la culpabilidad de vivir y de divinizar la razón como camino que conecta con el verdadero y aspirable mundo; pero con la ventaja de alcanzarlo en esta propia vida.

En la actualidad se ven las fallas de un sistema con claro déficit para formar a las personas en lo personal y vital: escaso sentimiento de ciudadanía, la generación nini, el abandono masivo de estudios básicos... Como apoyaría Ortega, antes de formar a un trabajador, dale un capital vital y humano con el que poder articularse y adaptarse a la realidad.

\subsubsection{Persona-masa, minoría selecta y la lucha vital}

Ya hemos analizado el problema del europeo medio -sin distinguir clase, género, sexo o edad- y de occidente, pues responde a un perfil generalizado. ¿Qué relación existe entre la debilidad vital, una falsa razón suprema y una posible rebelión de las masas? Como mejor transición, emplearemos una cita que relaciona directamente ambos libros: «Más importante que los antagonismos del pro y el anti, dentro del ámbito de una generación, es la distancia permanente entre los individuos selectos y vulgares» (Ortega y Gasset, 1981: 79).

Sin embargo, la sociedad necesita de una curiosa y compleja convivencia: la masa necesita una propuesta iniciadora, pero las alternativas minoritarias necesitan del resto y su aprobación para nacer. Esta es la esencia con la que se constituyen las generaciones, en cada una reside su misión. ¿Qué ocurre cuando esta queda desatendida? Inevitablemente surge un tipo de individuo que falsifica la vida (Ortega y Gasset, 1981).

Todo este proceso, su significado y alcance se explican en el segundo libro. Así, algunas de las cuestiones y preocupaciones sobre las que reflexiona Ortega y Gasset en La rebelión de las masas son: ¿qué es 
exactamente la persona-masa? ¿Por qué es tan peligroso que domine la sociedad, la cultura y la política? ¿Qué ocurrirá con el Estado y especialmente con una Europa decadente?

Esta cita nos puede ayudar a ver la potencialidad de un grupo y fenómeno social que causa gran interés en el autor. Como él mismo afirma «importa, pues, conocer mucho a fondo a este hombre-masa, que es pura potencia del mayor bien y del mayor mal» (Ortega y Gasset, 1990: 81).

Hasta que no decidamos uno de los dos rumbos estaremos cegados, vagamos perdidos en posibilidades y sumidos en el nihilismo negativo, tal y como sospechaba ya Nietzsche presente (Russell, 2011). Es la lucha vital del siglo XXI a gran escala, debemos recordar tal y como hemos explicado antes, que el europeo actual se caracteriza por un serio déficit para decidir y conocer la vida. Por tanto, la situación se agrava aún más, mientras no respondemos, cada minuto la Humanidad se aleja del avance social conseguido y se destaca que volver a escalar nuestros logros perdidos se vuelve un camino complejo y nada ni nadie asegure una completa recuperación (Ortega y Gasset, 1990).

Como propuesta propia, esta conexión dramática planteada por Ortega se podría considerar perfectamente una de las mayores vinculaciones entre ambas obras. Según tu postura vital y como se afronte, eres un tipo de individuo u otro. Estamos entrando aquí en la antropología filosófica orteguiana expresada propiamente en el segundo libro.

Ortega y Gasset empieza el libro planteando un hecho que se ha repetido a lo largo de la historia y ha traído consigo períodos decadentes: la presencia de aglomeraciones. O dicho de otro modo, todo se está llenando de muchedumbre. Para el autor son como parásitos de la sociedad que han venido a aprovecharse de sus recursos e incluso quieren decidir en ella. Por ese motivo, la masa quiere convertirse en la protagonista de la cultura y la política, es decir, básicamente de todo lo que influya socialmente.

La masa no se entiende ni responde a una clase social determinada, sino que depende del carácter y la actitud vital de cada persona. Es decir, la masa la integra un tipo de persona concreta y muy estereotipada; un ser humano vacío vitalmente, ignorante y estandarizado; bien malcriado, acomodado tanto como vago o sin ímpetu de formarse y vivir; todos falsifican su verdadero proyecto por el esfuerzo que le supone o aquel que no acepta la misión de su generación (Ortega y Gasset, 1990); en definitiva, en la sociedad actual quien no corrija los errores de la modernidad integrando la vida.

Como breve comparación personal, me recuerda mucho a la minoría de edad (Kant, 2005), donde aparecen individuos incultos, sin formación, que solo se mueven por ellos mismos y sus intereses y solo en casos concretos (imperativo hipotético), nunca de forma universalizable (imperativo categórico) pensando siempre y si es preciso anteponiendo el bien mayor. En este sentido, la élite nos recuerda a la mayoría de edad 
kantiana (Kant, 2005), la promesa de independencia, autolegislación y empoderamiento de la llustración. Para Ortega, una razón necesaria pero más sana y compensada.

El escaso y segundo colectivo: la minoría, formada por individuos especialmente exigentes, capaces de esforzarse y cualificados; genuinos y que afrontan la libertad vital del mejor modo que pueden; sin renunciar tal y como hemos visto a ninguna de las mitades; lo que tradicionalmente se ha ligado a la palabra ciudadano: pensando en el colectivo antes que en sí mismo. Dos modelos tan contrastados solo crean muchos problemas sociales: unos luchan por el avance de forma pacífica, otros abogan por sus intereses egoístas y de forma violenta (Ortega y Gasset, 1990).

La persona-masa huiría, por tanto, de la lucha vital, pero la vía para alcanzarla bastaría en cualquier momento con empezar a vivir de forma exigente y valiente, sin falsear la vida. Así pues, cualquiera puede vivir de este modo, al fin y al cabo es una cuestión de carácter y no tanto de clase o género. Afortunadamente para el destino de la humanidad.

\subsection{3 ¿La lucha vital posible tras la crisis mundial de la primera mitad del siglo $x x$ ?}

Después de resumir brevemente y aunar ambos libros, nos gustaría relacionar ese vacío existencial que en cierto modo dota Ortega a la persona-masa con algunas ideas muy llamativas. Hablaremos de la evolución de la segunda mitad del siglo xx, una etapa que Ortega no vivió, pero si vaticinó en aspectos importantes. Sin duda, este período se caracterizó por la gran lucha de ideologías de los grandes bloques en la Guerra Fría -comunismo contra capitalismo- que tanto arraigó y cambió al mundo. Abandonaríamos para siempre la escala local y continental y nos adentraríamos en hechos internacionales y un mundo interconectado por la globalización Rusell (2011) y Gamba (1987). Un concepto en la fina frontera de herramienta de occidentalización o la apertura de la verdadera sociedad intercultural como oportunidad de convivir y entendernos.

Durante la reconstrucción de la Europa destruida por los conflictos y unas colonias muy castigadas que se estaban descolonizando, apareció una población debilitada y sin respuestas, pues todo lo anterior -ya fueran fórmulas, sistemas, teorías, experimentos- había fracasado estrepitosamente. En esta época que bastó con sobrevivir, pero con completa ausencia de valores, ¿se puede hablar de lucha vital? Es una pregunta muy compleja, pero desde nuestra perspectiva: sí, al fin y al cabo sobrevivieron a un mundo destruido y poco a poco fueron deconstruyendo los valores previos y buscando alcanzar nuevos y mejores modelos. No hubiese sido posible sin la lealtad a uno mismo y el esfuerzo de sobrevivir a una época tan trágica y sin sentido.

¿Se les puede exigir responsabilidad histórica a los ciudadanos de dichas generaciones abatidas? Y más importante, ¿la situación ha vuelto a la normalidad o sigue distorsionada? ¿Existe un único modelo, el 
capitalista, o han aparecido alternativas competitivas? La sociedad, según Ortega, permanecerá en crisis y no podrá cumplir su labor generacional mientras solo exista la perspectiva consensuada de alcanzar la excelencia o lucha vital, y menos aún si está gestionada por las personas-masa.

\subsection{Lo profético en Ortega: sus reflexiones en la máxima actualidad}

De las múltiples ideas que hemos encontrado avanzadas a su época, por límites de extensión, solo podremos destacar las siguientes. En este apartado recogeremos la gran actualidad y utilidad de un autor que murió hace casi siete décadas, pero que supo anticiparse al cambiante mundo actual globalizado, lo que en nuestra opinión no es un mérito menor.

Primera idea, el nini actual equivale a la definición vital y visual de la persona-masa. Es un problema social y estructural de nuestro sistema actual. Como observamos, Ortega no falló en su pronóstico si combinamos ambos libros. El nini respondería a esa gente sin propósitos ni expectativas vitales, cuya falta de compromiso provoca que las deficiencias del sistema se agraven y perduren más.

Segunda idea a destacar, dentro del marco europeo, supo entender los límites autoimpuestos por el rígido concepto de la nación, y cada vez se volvió más necesaria una Unión Europea, para intentar salvar su decadencia (Ortega y Gasset, 1990). Aunque existen disonancias claras con la propuesta orteguiana, ya que esta no se constituyó como una supranación de unidad y diversidad, sino más bien como una empresa económica sujetada a los intereses capitalistas, ¿qué supone este cambio de postura? Un ejemplo muy claro de máxima actualidad: bajo la perspectiva de Ortega y Gasset, una Grecia débil debería ser ayudada sin exigencias ni pactos envenenados, aunque solo fuese por su legado clásico y por ser una nación hermana.

En el marco del conocimiento y el avance, el autor ya advertía de la confusión del progreso desde la modernidad. Nuestro autor sostiene que existe una necesidad obsesiva, entendido como el mal y excesivo uso de las herramientas - pese a su innegable potencialidad-, y una fe absoluta en la tecnología que ha derivado en el descuido del peso social y humano para mantener el complejo mecanismo de la civilización. O lo que es lo mismo: la deshumanización y la pérdida de las capacidades humanas en la sociedad (Ortega y Gasset, 1990). Proponemos un ejemplo muy claro: la incomunicación que produce el teléfono móvil supone una paradoja, pero... ¿cuántas veces hemos hablado con alguien tomando un café y este nos ha ignorado porque debía atender sus redes sociales? Es un ejemplo cada vez más común.

Finalmente, y en relación con el rumbo de la teoría democrática, Ortega y Gasset advierte del peligro de una democracia secuestrada y desatendida. Mientras que la élite raciovitalista queda bloqueada porque son menos y distintos, la ciudadanía en forma de masa y sin fuerza vital se vuelve pasiva y acomodada. Este descuido, que impide la bidireccionalidad entre exigencia real y actuación política, se traduce en la pérdida de unos derechos -considerados legítimos y básicos-obtenidos 
con mucha lucha social. Al mismo tiempo, en una época nihilista y sin valores, los nidos de corrupción aumentan como se puede apreciar en las noticias políticas de máxima actualidad. Esta idea subyace directamente si aunamos ambos libros.

\section{Conclusiones}

Tras la investigación y redacción del trabajo, hemos llegado a algunas conclusiones que exponemos en las siguientes líneas. En primer lugar, resumiremos la esencia del artículo: combinación de raciovitalismo y la sociología filosófica orteguiana para explicar problema -pero también la cura- en el ámbito individual, social y continental de Europa y su modelo occidental.

Como hemos visto a lo largo del libro, se entiende a la élite como la persona que busca responder al sentido de su vida y generación mediante lucha y esfuerzo vital. En ese sentido, la masa sería una persona perdida, acomodada o dormida entre las posibilidades de la vida, que reniega o dificulta su labor generacional. Cabe hacer especial hincapié en que Ortega en ningún momento habla de un estadio definitivo o natural; es decir, todo el mundo puede alcanzar la élite con esfuerzo. Al mismo tiempo, si esa minoría habitual se duerme en los laureles o cede su ilusión inicial también se volverá masa. $Y$ no basta con que lo piensa, pues al mismo tiempo se debe actuar -lo óptimo-o al menos criticar para ayudar a concienciar al resto de las deficiencias del sistema imperante. De este modo, y prácticamente solo así, se puede transformar y avanzar socialmente. Respondiendo al título: sí, todos podemos alcanzar la lucha vital y por tanto la excelencia, armonía y virtud del sabio (Aristóteles, 2015) y la mayoría de edad (Kant, 2001), integradas en concepto del autor.

En segundo lugar, hemos llegado a la conclusión de que la filosofía propuesta por José Ortega y Gasset goza de una gran vigencia. Nos ha llamado la atención el carácter profético que mantiene a lo largo de la obra, que incluye unas sorprendentes y agudas apreciaciones. Precisamente por ese motivo muchos lo consideran un sabio, ya que se adelantó varias décadas a su época y en fechas donde el rápido transcurso de los hechos y su área de influencia lo vuelven muy difícil de rastrear. Sin duda, uno de los principales intereses del trabajo era intentar evidenciarlo con sorprendentes resultados, ya que en ocasiones parecía un autor de la máxima actualidad.

En tercer lugar, nos gustaría advertir que parte de las complicaciones naturales de este trabajo ha sido comprender, conjugar y sintetizar tanto material de conocimientos en un espacio limitado; criticar y reflexionar a un gran intelectual como un estudiante aún en formación, y finalmente intentar buscar una escritura atrayente y clara sin perder calidad académica en el proceso. 
En cuarto lugar, un posible y potencial trabajo de investigación como apoyo al contenido de este, sería una comparación de Ortega con otros autores, pues se pueden encontrar un sinfín de conexiones que acercan nuestra filosofía a autores clásicos como Aristóteles (invirtuoso frente al sabio), Kant (persona-masa como minoría de edad egoísta frente al adulto cívico y empoderado capaz de actuar y pensar por todos, la élite). Por su antropología dual, lo podemos conectar con autores posteriores como Habermas y su ética discursiva (la masa usa la violencia, mientras la élite usa el diálogo) o la relación con superpersona o niño de Nietzsche con la minoría orteguiana. Al ver todas estas posibles conexiones, se demuestra la gran plasticidad del pensamiento orteguiano y se muestra el interés de retomar y ampliar las líneas del trabajo en un futuro.

Como conclusión final, viendo el peligroso auge de la persona-masa según las características e identificación propuesto por Ortega; nos preguntamos: ¿el egoísta persona-masa ganará una partida ya muy avanzada? ¿O aún estamos a tiempo de integrar razón, cultura, vida y biología de forma horizontal, armónica y necesaria? ¿Y de este modo aspirar al equilibrio sano y prudente aristotélico hacia un final feliz $y$ compartido? Al fin y al cabo, todo responde a actitud vital. ¿Usted, lector, qué opina? ¿Sabemos en el fondo cuál es la misión de nuestra generación? ¿Vive como élite o como masa? ¿Aprovecha su vida? En definitiva: ¿puede la persona-masa aspirar a la lucha vital?

\section{Bibliografía}

ARIStóteles (2015): Ética a Nicómaco, Alianza Editorial, Madrid.

GAMBRA, R. (1987): Historia sencilla de la filosofía, Rialp, Madrid.

KANT, I. (2001): Fundamentación de la metafísica de las costumbres, Alianza, Madrid.

Ortega y Gasset, J. (1981): El tema de nuestro tiempo, Revista de Occidente, Alianza Editorial, Madrid.

- (1990): La rebelión de las masas, Revista de Occidente, Alianza Editorial, Madrid.

RusSelL, B. (2011): Historia de la filosofía occidental, Espasa, Madrid. 